\title{
Smart Farming using IoT
}

\section{Harendra Singh Negi, Sushil Chandra Dimri, Kamlesh Chandra Purohit, Atika Gupta}

\begin{abstract}
Rural and urban areas in India face a variety of comparable problems within the domain of agriculture, which calls for certainly comparative answers for being coordinated towards finding these issues. The purpose of this concept is to analyze the ability of IoT techniques in relation to impoverishment in these areas, besides the requirements known in these commodities and with stress on farming. This work analyzes samples of an internet of things to modify the farming desires of the commodities for the region to maximize the yield production. In India, most of the peoples relay on agriculture and a big part of nation's income originate from the agriculture. Automation of agriculture method is one in all the crucial steps to our country, which needs to import immense quantity of crops from different nations to satisfy the need of peoples. The main challenge of the rural and urban agriculture area is that the correct observation of the land health, the environment, and arrange the spraying.
\end{abstract}

Index Terms: commodities, comparative, immense, spraying

\section{INTRODUCTION}

Agricultural information processing, conjointly said as agriculture is an area which approach farming info, farming progress and sensor devices to produce services regarding agriculture to upgrade technology, propagation, and knowledge delivery via information and communications technologies (ICTs) [1]. Agriculture's target on improvising farming and rural development by providing useful information to the farmers. Farming includes the conceptualization, architecture, advancement, analysis and different types of elements that uses Information Communication Technologies within the rural and urban area with a spotlight on agriculture industry [2]. Information Communication Technology is a protected term that features something from radio to mobile phones. There is developing significance within the future of web of things innovations to bolster poorness mitigation in rural areas mostly. The helping hand of this analysis is that the research of the possible inputs of Internet of Things to the area of agriculture for rural and urban areas in India. Internet of Things on the opposite hand is that the associating of phenomenal stuff to the net that assembles it attainable to approach remote detector knowledge and deal with this present reality [3]. The Internet of Things has the aim of rendering in ICT-framework which help the internet of things in an exceedingly protected and positive way, i.e., its objective is to beat the space between facts inside this present reality and their illustration in data framework [4]. The boost in Information Communication and

Revised Manuscript Received on April 25, 2019.

Harendra Singh Negi, Department Computer Applications, Graphic Era (deemed to be University), Dehradun, Uttarakhand, India.

Sushil Chandra Dimri, Department Computer Science, Graphic Era (deemed to be University), Dehradun, Uttarakhand, India.

Kamlesh Chandra Purohit, Department Computer Science, Graphic Era (deemed to be University), Dehradun, Uttarakhand, India.

Atika Gupta, Department Computer Science, Graphic Era Hill University, Dehradun, Uttarakhand, India.
Technology availability, openness and versatility have brought about their utilization even at interims country address wishing on horticulture. The operator of information communication and technology in agriculture are: 1) Nominal priced and common goods, 2) full major and more cost efficient devices, 3) progresses in detail stockpiling \& interchange, 4) inventive work images and associations, 5) appeal for horticultural message servicing [4]. Whatever ICT interposition that increase the job of needy farmers can have powerful immediate and circuitous encounter on improvising farming yields, selling \& post cropping exercises that successively will devote to poorness minimization [5]. To the entire rural areas, the hurdles have needed to be self-labeled by Information Communication \& Technologies are: 1) area hurdles, i.e., introduction to ministry authority service, 2) budgetary hurdles, i.e., introduction to broad work \& work markets, 3) association obstacles of provincial national access to instruction and preparing, wellbeing, social administrations, and so forth 4) desirable creation, \& administrations. [6].

\section{PROBLEM STATEMENT}

Rural and urban areas in our country face variety of similar problems within the field of agriculture, communion framework, water resources, highway \& transport, passage to markets, healthiness \& schooling, that entails identical however regionally significant result to be organized towards determination problems associated with these similarities [7]. So as to reply to the requirements of the agricultural commodities, mitigate poorness and slim the intelligence partition among town and village areas, this analysis suggest the acceptance of knowledge and ICTs, specifically IoT, to dispatch servicing to rural commodities of our country [8]. The objective of this analysis is to spot desires and suggest internet of things in return to those desires which will share to change the impact of poorness within the rural domain of our country.

The queries asked are:

- What are the rural desires of the agricultural commodities that, once self-interest, can cause the upliftment of their lives and poorness mitigation [9]?

-What internet of things automation are breathing and what internet of things will within the coming up architecture and developed to fulfill these requirements.

The analysis aim can be:

- Analyze current research on the rural challenges in our country [10].

- Establish the internet of things automation which will direct these requirements via use cases.

In the name of directing the analysis drawback, an informative path is employed [11].

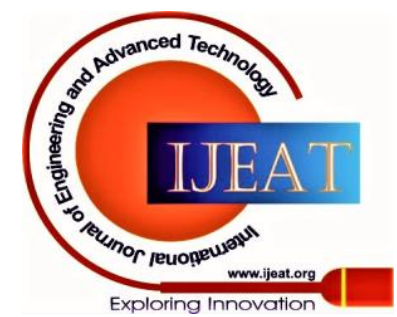




\section{Smart Farming using IoT}

The interpretative path is based on subjective strategies to get and analyze information. It is difficult to upgrade analyzer's discerning of human behavior and action because it describe to the development underneath inspection [12].

It's supported the concept that information of actuality will be perfect capture via common development that includes papers, shared context, etc. [13]. A literature analysis was organized on each the rural challenges of the agricultural commodities, and internet of things technologies which will be accepted to fulfill the requirements. The end product is support on internet of things advancements for the territory of farming, wanting especially at answers to the known desires [14].

\section{ARCHITECTURE OF INTERNET OF THINGS}

The most basic architecture is a three-layer architecture as shown in Figure 1. It was introduced in the early stages of research in this area. It has three layers, namely, the perception, network, and application layers.

(i) The perception layer is the physical layer, which has sensors for sensing and gathering information about the environment. It senses some physical parameters or identifies other smart objects in the environment.

(ii) The network layer is responsible for connecting to other smart things, network devices, and servers. Its features are also used for transmitting and processing sensor data.

(iii) The application layer is responsible for delivering application specific services to the user. It defines various applications in which the Internet of Things can be deployed, for example, smart homes, smart cities, and smart health.
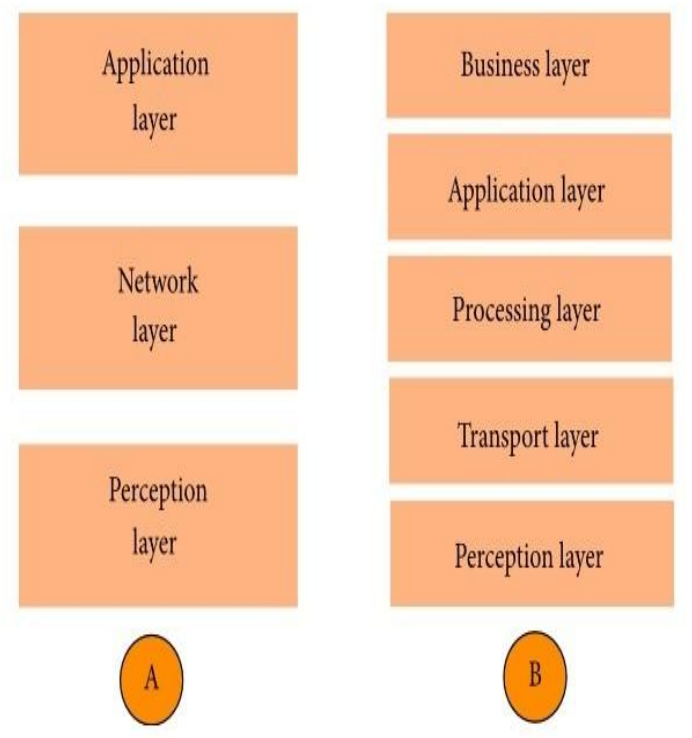

\section{Fig. 1. Architecture of IoT (A: Three Layers) (B: Five Layers)}

The three-layer architecture defines the main idea of the Internet of Things, but it is not sufficient for research on IoT because research often focuses on finer aspects of the Internet of Things. That is why, we have many more layered architectures proposed in the literature. This architecture additionally includes the processing and business layers [15]. The five layers are perception, transport, processing, application, and business layers. The role of the perception and application layers is the same as the architecture with three layers. We outline the function of the remaining three layers.

(i) The transport layer transfers the sensor data from the perception layer to the processing layer and vice versa through networks such as wireless, 3G, LAN, Bluetooth, RFID, and NFC.

(ii) The processing layer is also known as the middleware layer. It stores, analyzes, and processes huge amounts of data that comes from the transport layer. It can manage and provide a diverse set of services to the lower layers. It employs many technologies such as databases, cloud computing, and big data processing modules.

(iii) The business layer manages the whole IoT system, including applications, business and profit models, and users' privacy. The business layer is out of the scope of this work. Hence, we do not discuss it further.

\section{POTENTIAL IOT SYSTEM IN AGRICULTURE}

In The following areas provides a less samples of possible operations of internet of things in rural and urban areas of agriculture. To the agriculture functions and in a surroundings wherever the appearance of global conditions and output in unreliable downfall arrangements, machine-driven weep soaking is adapted [16]. Weep soaking is that the yield soaking method that waters solely the land nighest to the weed's origin. Joining knowledge on temperature, wetness and land's water content collected by numerous sensor devices, authority not solely where water is discharged however what quantity is required. Since the agriculture square measures are dowered with sustainable efficiency and there's less/no access to the electricity network, these sustainable efficiency techniques like star and air will grain efficiency towards water force that successively force the water from under-ground into pool. This water is employed to spray yields. Climatology has done through investigation of atmosphere data over long time to reduce agrarian danger. This is offered as massive knowledge study. In climatology for tormenter board, humidity, yield type, land fertility, plants status, temperature, air and soil wetness square measure gathered at native level via sensor devices [17]. The pest's wheel of life is scanned at the side of the weather knowledge, permitting analyzers to suppose tormenter burst a lot of precisely as a result of tormenter evolution depends on inconclusive mode. So that regular larceny, animal's square measure fitted with oftenness RFIDs that alter pursuit of the wild. The situation of the wild-animal is unreal on a picture in an exceedingly management inmost completed knowledge address wirelesses. In backcountry wherever there is communistic feeding, creature look to urge invisible. Livestock are matched with RFID chips and lectors square measure situated at numerous watching flaws to broadcast info to our cultural branch maintenance room. The location of animal is challenge [18]. The internet of things may alter branch-less funding supply. Agriculturalist can transfer, money, and pay debts that embrace stores, to the advantage of agriculture commodities, our agencies don't have any rights to reserve inside an acceptable area.

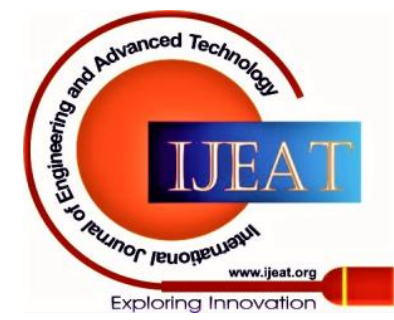


A territorial value data structure keep gather knowledge from the most domestic markets and refine it out to native equivalent via tiny info centres that have net accessibility. In additional unusual commodities, two way or agricultural transmission is accustomed program costs to ample public. Asteroid lightweight diffusion will notice decomposition within the overwhelming waterways [19]. It utilizes the cognizance of contamination to characterize the class of waste product. This technique become convenient in cultivation. Alluvion may be a drawback in watercourse bay. An internet website is started with actual time appearance of a geographic region. The power to ascertain what circumstance all through a geographic region and proceed rapidly to dynamical pneumatic and climate arrangements will safe plenty of lifes in rural commodities. Sensor devices guide the surroundings within the watercourse bay and wirelesses feed info into the web site.

The internet of things technology will guide exactitude rural-agriculture, a mode of farming whose aim is to magnify come back on financing in rural areas for agriculture. Spraying or water-detection or land-detection sensor devices provide alerts to assist / defend an agriculturist yield and spread message wire-lessly to water resources place on once to spray. Moreover, agriculturist will adopt machine-controlled weep spraying in field wherever water is limited. This may be managed by joining information from numerous sensor devices that manages not solely where water is discharged however what proportion desired [20].

For the sake of attenuate yield harm by creeper feeding plague, creatures and veldt coals through others, higher in field observance is needed. This may be cultivated by designing sensor devices that supervise the farms. These are going to be ready to notify agriculturist of any strike on their yields / flames spotted before they unfold.

Numerous Decision Support System that run on sensible devices like phone backing agriculturist arrange for the subsequent gardening period. In reserve, these functions facilitate agriculturist distinguish yield and calves defect and dictate prescription to the known defects. Instead, in many cases wherever an agriculturist visits many veterinaries executives, village peoples will carry sensible healthiness cards [21]. The cards will have store all animal's information and is restored at each visit to the veterinary executed. For medication to rural area farmers, sensible devices is accustomed snapshot and convey images of troubled stock or yields to specialists our nation agency dictate remedies to the issues known.

\section{A. System Structure}

The Internet of Things stage outline thought is connected to the ongoing observing arrangement of soil dampness and supplement. The framework is partitioned into three layers: Physical layer, Network layer, and Application layer. The general framework structure is appeared in Fig. 2.

Physical layer: This layer is for the most part to accomplish information obtaining and recognition [22] including soil moisture, temperature, humidity, and soil supplements. As per the investigation, we found that the temperature and humidity at various soil profundities at a similar area can better mirror the ecological condition. So we utilize single-point multi-layer identification strategy and the dirt profundity of $20 \mathrm{~cm}, 40 \mathrm{~cm}$ and $60 \mathrm{~cm}$ was chosen for observing. Soil moisture is measured by a unique soil moisture sensor which can understand on-line location. The yield voltage of the sensor shifts with the change of soil water content. Soil temperature and humidity are measured utilizing advanced temperature and humidity sensors. There is no appropriate on-line soil supplement location sensor. Supplement change is moderate and the estimation takes a drawn out stretch of time. Along these lines, the convenient soil supplement finder is chosen to distinguish soil supplements.

Network layer: It for the most part incorporates remote sensor system and information transmission offices associated with the Internet. The information transmission organize incorporates the short-remove transmission some portion of the yields and the information long-separate transmission part. IoT Gateway is the center of remote sensor arrange gear which can accomplish association with the general population system and convention transformation. The short separation transmission in the dirt uses GSM innovation, and remote sensor organize innovation [23], which has the benefits of low power utilization, solid portability and different focal points in arrangement and upkeep. The long-separate transmission utilizes GPRS [24, 25] to interface with the Internet server, which underpins IPV4 and IPV6 on the transmission convention. The ideas of talk and chatter steering calculations are broadly utilized in sensor systems and specially appointed systems. So we additionally utilize this strategy in our framework. The primary capacity of this layer is to transmit different horticultural data gathered by the recognition layer to the foundation arrange server through the system.

Application layer: It is an incorporated data stage in view of business rationale. The product running on the stage incorporate a sensor organize administration framework, a WEB GIS-based checking information inquiry and investigation framework, and a harvest accuracy preparation choice emotionally supportive network. Sensor arrange administration framework proposes ideal format suggestions in light of the sensor organize improvement conveyance display. The information question and examination framework in view of WEB GIS can get the humidity, temperature and supplement estimation of soil. The information are acquired from the ongoing checking database of the sensor arrange in the GIS spatial database through information blame amendment.

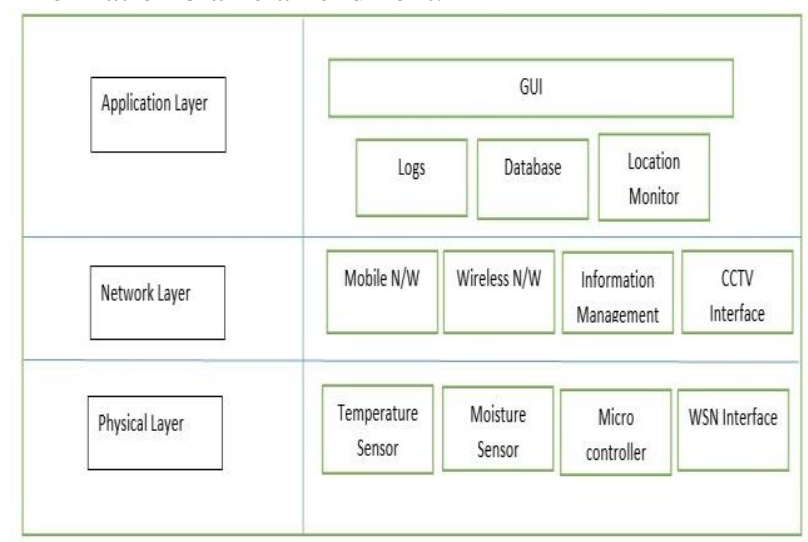

B. Sensor Node Structure

Fig. 2. System Structure

Published By: 


\section{Smart Farming using IoT}

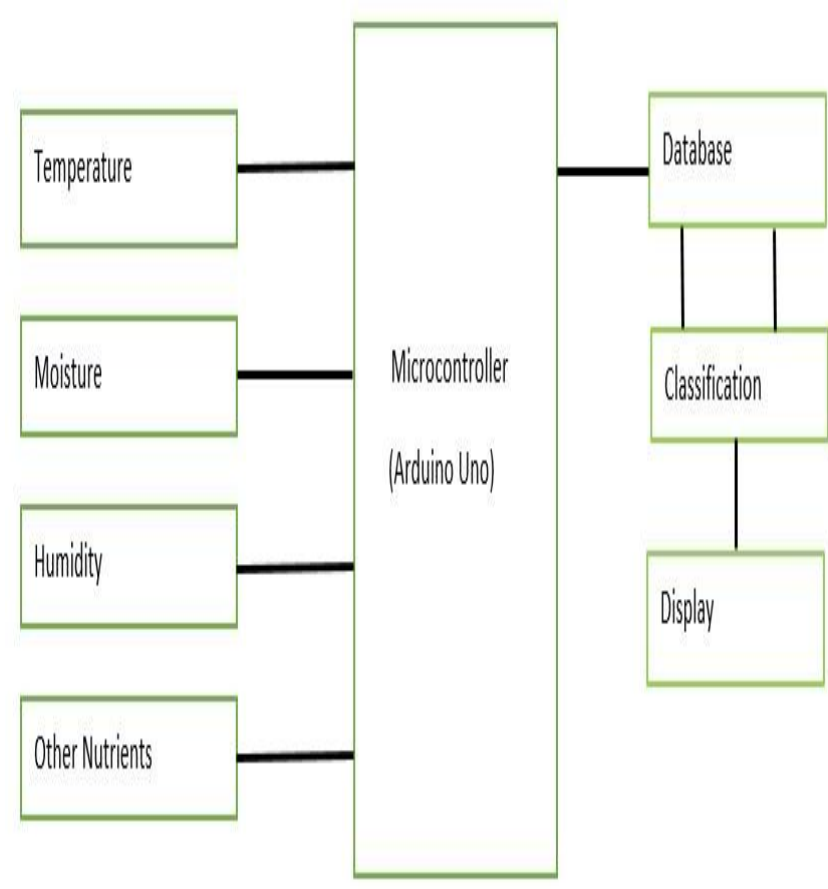

Fig. 3. Sensor Node Structure

The primary assignment of the sensor control node is to gather the soil temperature, humidity, moisture and other parameters, and transfer data to the master node i.e. microcontroller. We select the soil temperature sensor, soil humidity, soil moisture sensor. These sensors have the qualities: they have fast response time, higher accuracy, broad range, good stability. This microcontroller module is a series of surface mount modules that enable users to realize WSN compatible system in the shortest time and at the lowest cost. The field sensor can send the data to the micro control node through the WSN or any other device. Fig. 3 explain how sensors are deployed on microcontroller.

\section{Work Flow Diagram}

The framework will begin its working as the client approval will happen with right username and password. On the off chance that username and password, neither of them matches, then the framework will end. On the off chance that username exists and the password is right then the introduction of the framework will occur, by initialization, it implies that every one of the sensors which is deployed, for example, humidity sensor, water level pointer sensor, and temperature sensor will be introduced to zero, thus restarting the memory including information or filed values if any showed.

The information consequently detected by the sensors i.e. temperature of the earth, soil moisture content, water level, every one of these elements are detected will be gathered and exchanged to the base server station situated in the field. The base server station will additionally exchange the information to the main server framework over a solid convention. The main server station will break down the information sent by the base server station situated in light of the limit values set for every substance. The dissected information will then be shown to the client. In light of this outcome, the rancher can take the choices as needs be which are great for the productive cultivating. In the event that the farmer wishes to proceed with the framework information then as opposed to leaving it will advise the framework to proceed and the sensors will be instated again rehashing the entire cycle.
On the off chance that the client is fulfilled and needs to leave the framework, then the client will exit and the framework will end. Fig. 4 demonstrates how the framework will carry on from client login to client logout. All the accessible exercises are appeared in the fig. and in addition central framework, Base station framework and Data analysis framework, these elements are enrolled which are key substances of the design. How this calculation functions can be better comprehended by taking a gander at depictions of GUI's which will demonstrate the alternatives accessible for client.

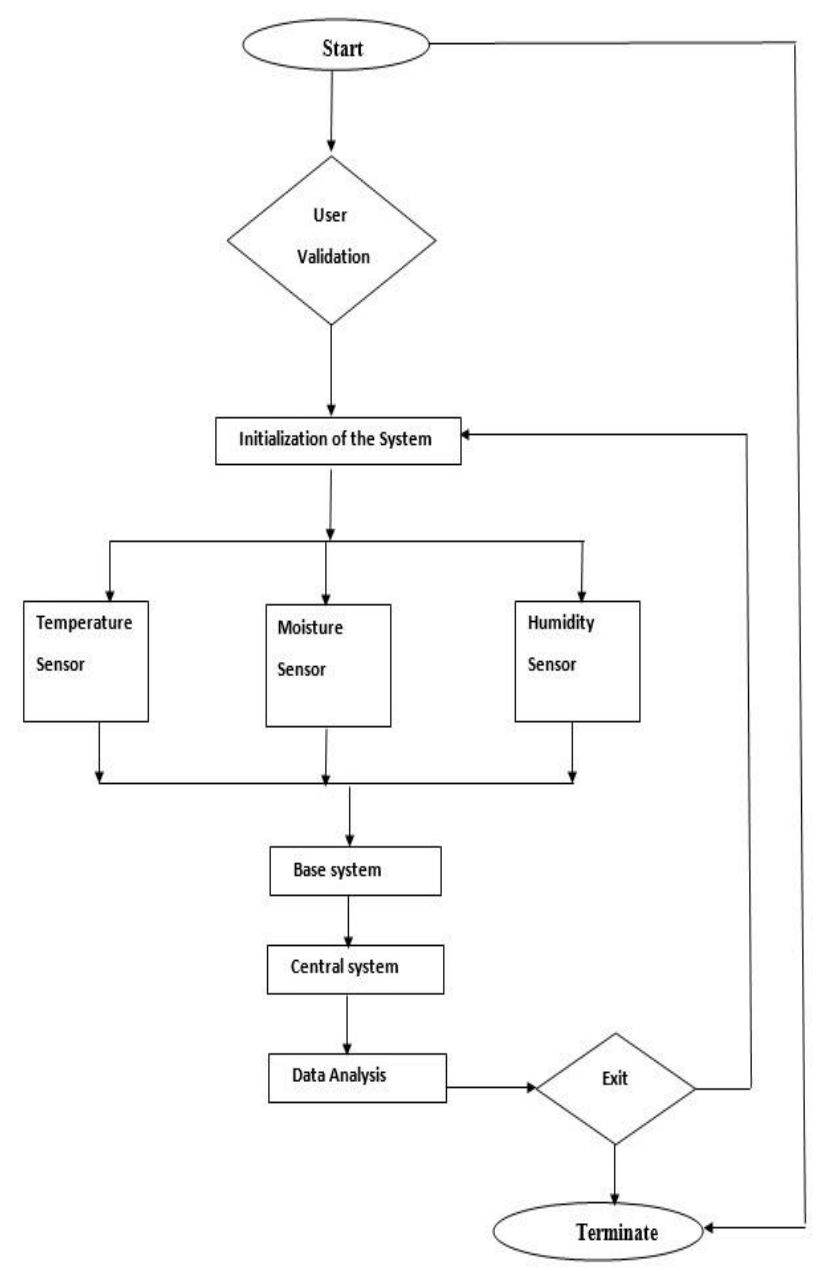

Fig. 4. Work Flow Diagram

\section{PROPOSED SYSTEM}

The objective of this analysis is to spot associate degreed increase a responsive requirements of Indian rural agriculture areas and what interference may be rendered in terms of IoT technology. These IoT techniques have implied to mitigate impoverishment and improve the quality of living of the agriculturist. As a sample, biological planthouse form it potential to rise a field of good yields that may not only be spend regionally however conjointly transport to different nations [26]. This allows agriculturist to come up with additional financial gain that help to improve their customary of developing and additionally to contribute to the GDP.

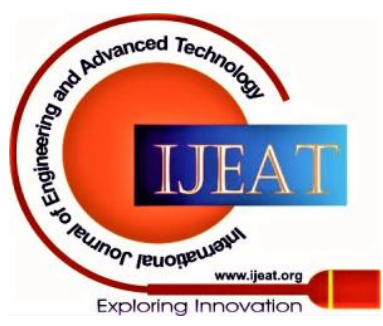


The agriculturist may also pull the expenses within the internet of things (IoT) technologies that backing rural areas to boost the quality of developing [27].

Since internet of things (IoT) technologies simplify the pursuit of soil product, all the thanks to their objective, this can be optimal for soil product so that they needs more process seeing that the patrons will understand earlier, once the soil product can visit and arrange for the coming process in time [28]. Since agriculture commodities unit surely inhabited, shipment of soil product is an issue. Internet of Things technologies will legitimize the shippers by rendering info of agriculturist. Thus shippers don't have to be compelled to hold till they load a truck with farm product to begin off, and they can go-ahead any time rendering the field unit, they know that there are agriculturist looking forward for transport ahead.

\section{A. Agriculture Monitoring Service}

The farming checking administration is an administration to store in the database ecological and soil data gathered from the sensors deployed outside, and enable clients to screen agribusiness data about the planted yields by means of Database anyplace progressively. Take a at the activity of this administration, the sensors introduced in the outside gather natural and soil data and occasionally sent the detecting information to the sensor chief, at that point the sensor director parses and dissects the got detecting information to remove each detecting quality and change over its organization to store it into each table of the database. The WSN brings soil data on the outside put away in the database to send it to a GUI at customary interims, and clients can screen the outside condition data on by means of the GUI. Fig. 5 demonstrates the working procedure of the horticulture checking administration.

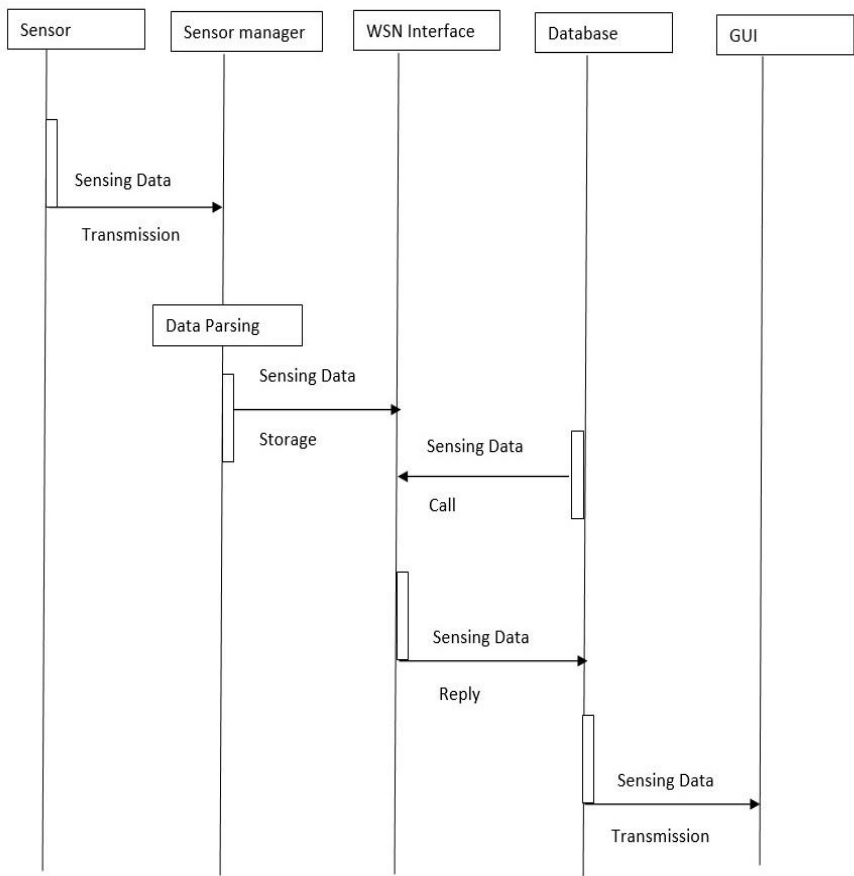

Fig. 5. Operation Process of Agriculture Monitoring Service

\section{B. Data Model for Data Processing}

This system has developed to take decisions for farming under constant condition. The work compared real time environment information to the real time factors. Also, this part analyzed information about disease to the every crop and predicts the type of real and actual data.

To construct data model based on IoT is shown in fig. 6 .

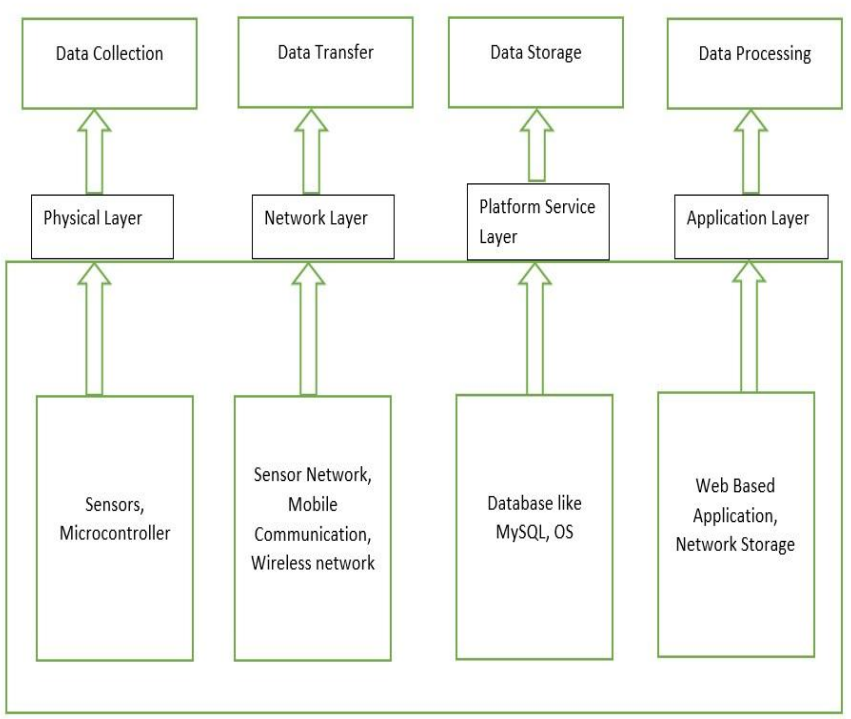

Fig. 6. Data Model for Data Processing

Physical layer is one of the Main layers to keep track of field data like temperature, moisture. We have to install these sensors on a microcontroller board.

Network layer is responsible to design a network in which data will be transmitted from one location to another. The transmission can be wired or wireless.

Platform service layer maintain the database part where we'll store data in the database.

Application layer provide the user interaction. In this layer, we maintain the GUI part. With this part we can access our data and also we can save our information in the database.

\section{RESULT ANALYSIS}

The analyze results are shown in the form of moisture, temperature, and $\mathrm{Ph}$ value to alert farmer about soil in the given figures such as fig. 7 , fig. 8 , and fig. 9 .

The collected data shown in the figures are stored on the server.

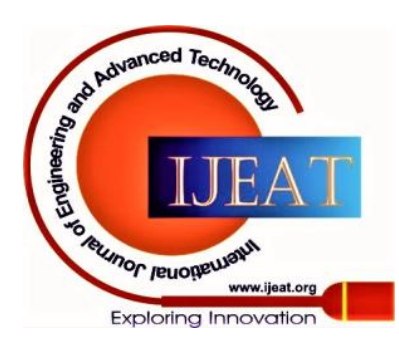




\section{Smart Farming using IoT}

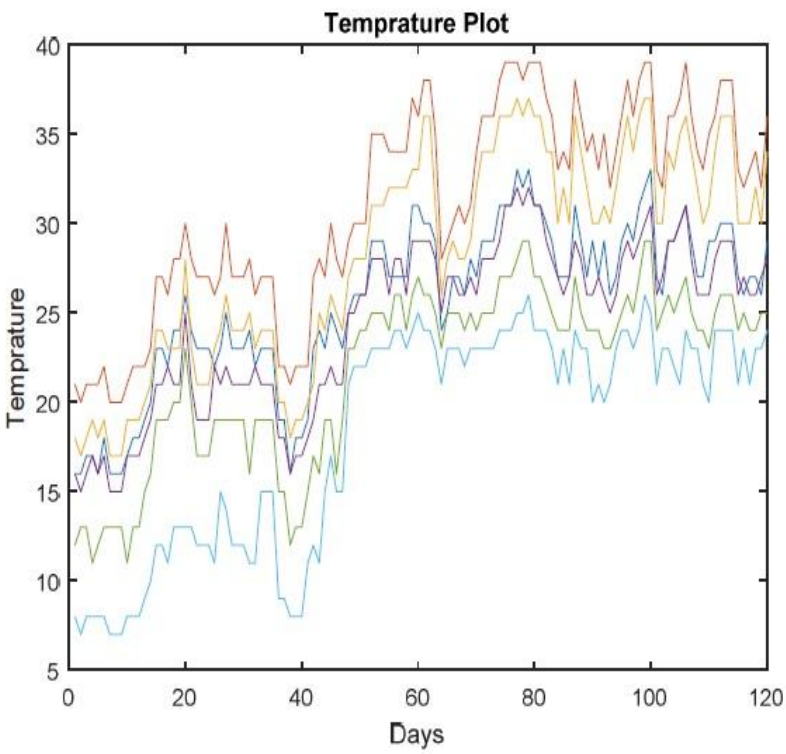

Fig. 7. Temperature Graph

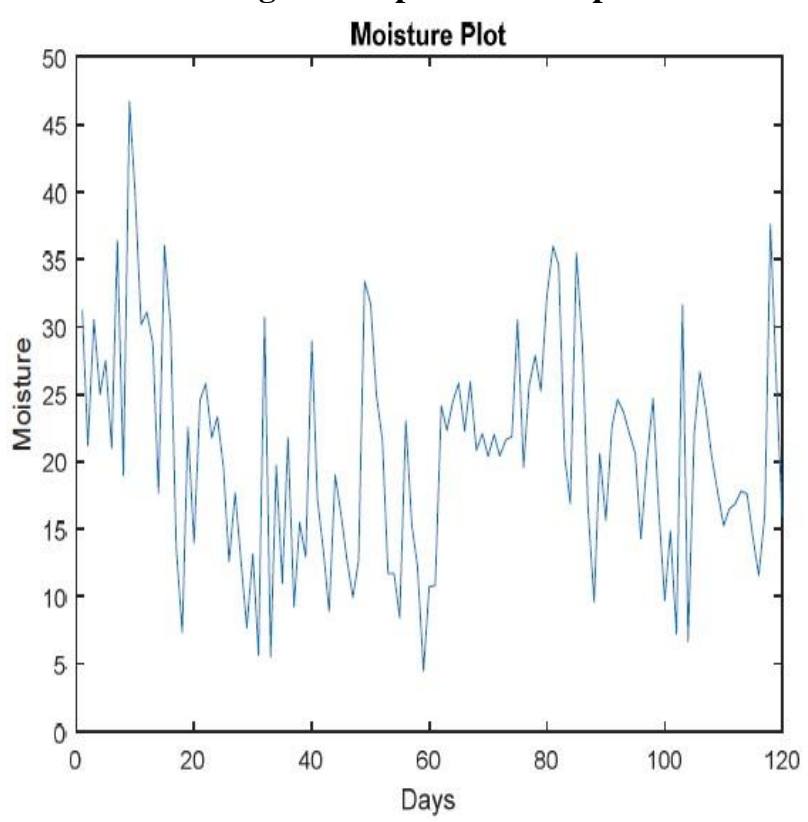

Fig. 8. Moisture Graph

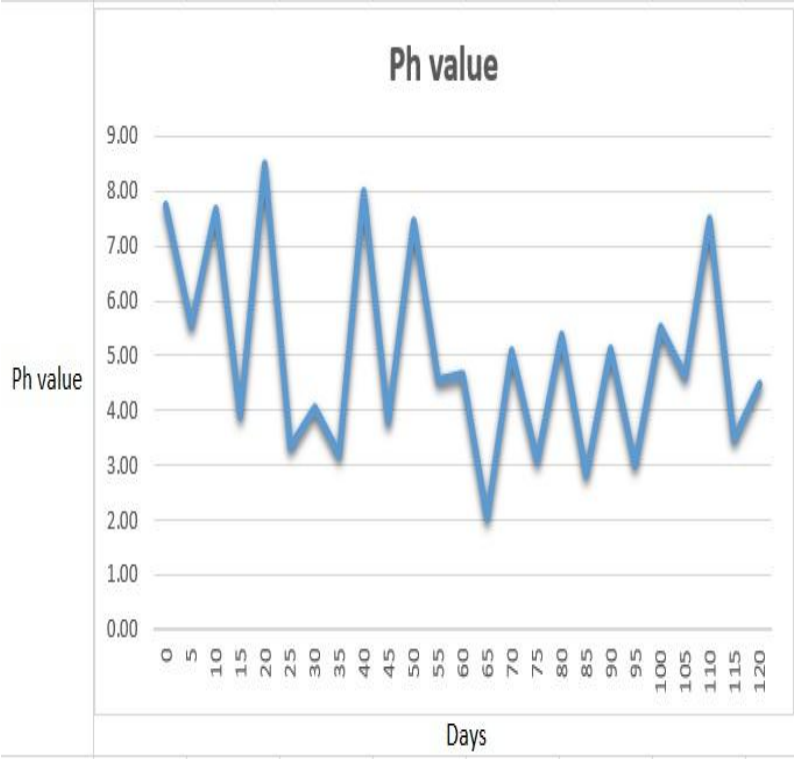

Fig. 9. Ph Value Graph

Fig. 7 shows a Soil Temperature data which is received over 120 days at different time intervals separately on a normal stretch premise. It is clear from the graph that how the temperature shifts. The calm ascents in any case, stays pretty much consistent somewhere in the range of 40 and 120 days. Fig. 8 shows a Soil Moisture information which is received over 120 days. The graph shows the varieties in the soil moisture. When values will felled under 10 can be considered as an alert for farmers.

Fig. 9 shows a Soil $\mathrm{Ph}$ values information which is received over 120 days are used to measure acidity. If $\mathrm{Ph}$ values lies between 6.5 to 7.5 then it is neutral. If $\mathrm{Ph}$ values are greater than 7.5 then it is alkaline. If $\mathrm{Ph}$ values are less than 6.5 then it is acidic but if it is less than 5.5 then it is strongly acidic. Fig. 9 shows how $\mathrm{Ph}$ values are changed.

\section{CONCLUSION}

The result has known possible functions of IoT in rural and urban areas for feasible agriculture evolution. It shown the benefits which will be derived from internet of things by many regions of rural areas as well as urban areas. These regions embody water administration, meteorology, life administration, investments, weed and infection administration, shipment and storage of rural-agricultural manufacturing. The research is supposed to significance guideline on the acceptance of internet of things in rural and urban agriculture. The research may be utilized by researchers of latest internet of things (IoT) technologies to create nation specific techniques supported the known. The agricultural folks can develop once the techniques are refined to guide poorness mitigation and rising the specification of the individuals.

\section{REFERENCES}

1. Gakuru, M., winters, K., Stepman, F., Inventory of innovative farmer advisory services using ICTs, The Forum for Agricultural Research in Africa FARA, 2009.

2. Handbook of Research on ICT in agricultural development, edited by M.S. Naorem and T.M. Chanu, 2011

3. Kopetz, H., and Internet of things: design principles for distributed embedded applications, Real Time System Series 2011, pp. 307-323, Springer, US, 2011.

4. Strtigea, A., ICTs for rural development: potential applications and barriers involved, Networks andCommunication Studies, vol. 25, no. $3 / 4$, pp. 179-204, 2011

5. Rouhani, Q.A., Brits, P.J., Report WRC: TT235/04, Rhodes University, 2004.

6. Fadzilah Siraj and Nureize Arabiya, "Integrated Pest Management System Using Fuzzy Expert System”, www.repo.uum.edu.my/1928/.

7. De Villiers, M.R., Three approaches as pillars for interpretive Information Systems research: Development research, action research and grounded theory, SAICSIT 2005, South Africa, 2005.

8. Bernesten, K.E., Osterlie, T., Interpretive research methods in computer.

9. S. R. Nandurkar, V. R. Thool, R. C. Thool, "Design and Development of Precision Agriculture System Using Wireless Sensor Network", IEEE International Conference on Automation, Control, Energy and Systems (ACES), 2014.

10. Agarwal, R. and Karahanna, E. Time flies when you're having fun: Cognitive absorption and beliefs about information technology usage, MIS Quarterly, vol. 24, no. 4, pp. 665-694, 2000

11. Agriculture, livestock and fisheries: sector profile, http://www.zda.org.zm/content/agriculture.

12. Q. Wang, A. Terzis and A. Szalay, "A Novel Soil Measuring Wireless Sensor Network", IEEE Transactions on Instrumentation and Measurement, pp. 412-415, 2010. 
13. Cousins, B., What is a smallholder? Class analytic perspectives on small-scale farming and agrarian reform in South Africa, http://www.plaas.org.za/pub2/downloads/wp16/

14. Maumbe, B. M.; Okello, J. Uses of Information and Communication Technology (ICT) in Agriculture and Rural Development in Sub-Saharan Africa: Experiences from South Africa and Kenya. International Journal of ICT Research and Development in Africa, vol.1, no. 1, pp. 1- 22, 2010

15. Pallavi Sethi and Smruti R. Sarangi, " Review Article Internet of Things: Architecture, Protocols, and Applications, 26 Jan 2017.

16. Donovan, K., Anytime, anywhere: mobile devices and services and their impact on agriculture and rural development, overview of ICT in agriculture: opportunities, access and cross-cutting themes, 2011.

17. Baker, N. ZigBee and Bluetooth - Strengths and weaknesses for industrial applications. Comput. Control. Eng. 2005, 16, $20-25$.

18. Joe-Air Jiang, Becoming technological advanced - IOT applications in smart agriculture, APAN 38th meeting, 11-15 August 2014.

19. Mohd Fadlee Abd Rasid, Borhanuddin M Ali, N Abd Kadir, Putrajaya, Embedded Decision Support System (DSS) for IoT Application in Precision Agriculture, University of Malaysia, Malaysia , 2014

20. Nomusa Dlodlo, Council for Scientific and Industrial Research and Josephat Kalezhi, Copperbelt University "The Internet of Things in Agriculture for Sustainable Rural Development".

21. Weber, R.H., Weber, R., internet of things: legal perspectives, Springer Berlin Heidelberg, pp. 1-22, 2010.

22. Zhou, Y.M. Yang, X.L Guo, X.S. Zhou, M.G. Wang, L.R. "A Design of Greenhouse Monitoring \& Control System Based on ZigBee Wireless Sensor Network", in Proceedings of 2007 International Conference on Wireless Communications, Networking and Mobile Computing (Wi Com 2007), Shangai, China, 21-25 September 2007.

23. Peter B Goodell, Richerd E. Plant, Thomos A. Kirby, Joyce F. Strand, L. Ted Wilson, Lowell Zelinski, Julli A. young, Andrew Corbett, R.D. Herrick, Ronald N. Vargas, (1990), "CALEX/ Cotton: an integrated expert system for cotton production and management", California Agriculture, Vol 44, No. 5.

24. Flawed Baig, Naima Nawaz \& Serif - Ur - Rahman (2005),"'Expert System For Decision Making In Agriculture Sector", Journal Of Agriculture and Social Science, 1813-2235/2005/1-2-208-211.

25. C. Dale Monks, David C. Bridges, John W. Woodruff, Tim R. Murphy and Daniel J. Berry (1995)," Expert System Evaluation and Implementation for Soybean (Glycine max) Weed Management", Weed Technology Vol. 9, No. 3 (Jul. - Sep., 1995), pp. 535-540, Weed science Society Of America. URL: http://www.jstor.org/stable/3987669.

26. Howard W. Beck, Pierce Jones and J.W. Jones (1989),” SOYBUG: An expert system for soybean insect pest management", Agricultural Systems, Vol. 30, Issue 3, 1989, URL http://www.sciencedirect.com/science/article/pii/

27. Jaiganesh.S, Gunaseelan.K, V.Ellappan," IOT Agriculture to improve

28. Food and Farming Technology ", Proc. IEEE Conference on Emerging

29. Devices and Smart Systems (ICEDSS 2017) 3-4 March 2017, Mahendra Engineering College, Tamilnadu, India.

30. Carlos cambra, Sandra sendra, Jaime Loret, Laura Garcia , "An IoT

31. service-oriented system for Agriculture Monitoring", IEEE ICC 2017

32. SAC Symposium Internet of Things Track.

\section{AUTHORS PROFILE}

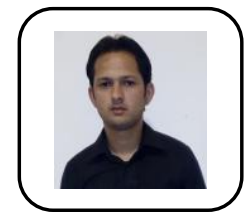

Harendra Singh Negi, He is assistant professor in department of computer Science and Engineering graphic era (deemed to be university) Dehradun. He did his masters M.Tech.(CS) form Graphic Era (deemed to be university) and MCA from HNB Garhwal University. His main research are is IOT and

cloud security.

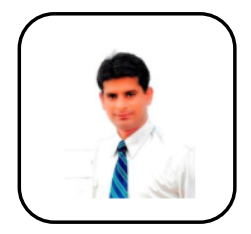

Dr. Sushil Chandra Dimri, He is Professor of the Department of Computer Science in the Graphic Era University. He received his Ph.D. in Computer Science from the Kumaun University, India, a Master's degree in Computer Science from the ISM, Dhanbad, India, His main research areas are network services in mobile networks, cyberspace and cyber security, Analysis and Designing of Algorithms, and so on.

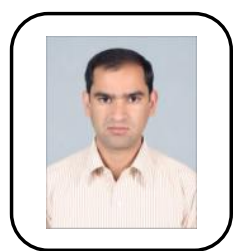

Dr. Kamlesh Chandra Purohit, He is an Assistant Professor of the

Department of Computer Science in the Graphic Era (deemed to be University). He received his Ph.D. and Master's in Computer Science and Engineering from the Graphic Era (deemed to be University), India. His main research areas are cloud computing, network Security in mobile networks, cyber security and so on.

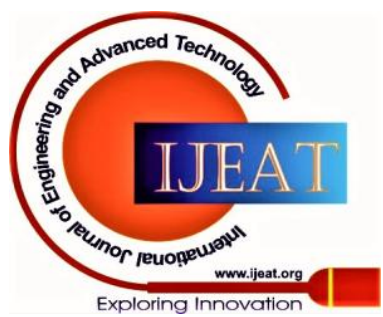

